\title{
EFECTOS DE LA COMPOSICIÓN DE LA DIETA SOBRE LA UNIFORMIDAD AL FINAL DEL CICLO DE POLLOS DE ENGORDE
}

\author{
Effects of Diet Composition on Uniformity at the End of the Cycle in \\ B roiler Chickens
}

\author{
Juan Carlos Terraes ${ }^{1,2}$, Martín Sindik ${ }^{1}$, Fernando Revidatti ${ }^{1}$, Ricardo Fernández ${ }^{1}$, \\ Andrea Biloni ${ }^{1}$, José Rafart ${ }^{3}$
}

\section{Resumen}

\begin{abstract}
El estudio describe la evolución del porcentaje de uniformidad de un lote de pollos parrilleros machos, donde el objetivo fue determinar el efecto del empleo de dos dietas isocalóricas con bajo y alto nivel de proteína. Se empleó 196 pollos parrilleros machos divididos en los dos grupos experimentales. Los porcentajes de uniformidad, al final del ciclo de engorde (día 49) fueron de $68 \pm 13 \%$ y $72 \pm 12 \%$, para las dietas A y B, respectivamente, sin que se encuentren diferencias durante la evolución de la variable durante el ciclo ni al final del mismo. No obstante, el análisis de las medidas repetidas detectó diferencias significativas para la uniformidad, independientemente de los tratamientos $(\mathrm{p}<0.05)$, destacándose un marcado descenso en la variable de estudio hacia el final de la primera semana (55\%), con respecto al valor inicial, cuyo promedio general se situó en $90 \%$. Los resultados indican que, a pesar de las diferencias en la composición química de las raciones evaluadas, ambos tratamientos presentaron idéntica respuesta en los porcentajes de uniformidad, lo cual, y debido al costo diferencial de las raciones asociados a los niveles de proteína, se puede concluir que la falta de diferencias estadísticas entre las dietas establece un hallazgo importante a la hora de considerar la relación costo beneficio de la producción.
\end{abstract}

Palabras clave: avicultura, nutrición, principios nutritivos, relación energía/proteína

\section{Abstract}

This paper describes the uniformity in broiler chickens, where the objective of the study was to evaluate two types of isocaloric diets with low and high protein level. A total of 195 broiler male chickens distributed in the two experimental groups were used. At the end of the production cycle (day 49), the uniformity for both diets were $68 \pm 13 \%$

${ }^{1}$ Cátedra Producción de Aves, Facultad de Ciencias Veterinarias, Universidad Nacional del Nordeste, Corrientes, Argentina

${ }^{2}$ E-mail: jcterraes@hotmail.com,granja@vet.unne.edu.ar

${ }^{3}$ Módulo de Reproducción Avícola, Instituto Nacional de Tecnología Agropecuaria(INTA). Las Breñas, Chaco, Argentina 
and $72 \pm 12 \%$ respectively, and without statistical differences between groups throughout the production cycle or at the end of it. However, repeated measures analysis showed significant differences for uniformity, regardless of treatment $(\mathrm{p}<0.05)$, as there was a marked decrease in the variable of study towards the end of the first week (55\%) as compared to the initial value of $90 \%$. The results indicate that despite the differences in chemical composition of the tested rations, both treatments showed similar percentages of uniformity, and if considering the differences in costs due to the levels of protein in the rations, it can be concluded that the lack of statistical differences between diets provides an important finding when considering the cost benefit analysis of production.

Key words: poultry, nutrition, nutritional principles, energy/protein ratio

\section{INTRODUCCIÓN}

El nivel de uniformidad en los lotes de pollos de carne es un buen indicador del proceso productivo, dado que todos los problemas técnicos o de salud, desde el primer día de cría del reproductor parrillero hasta la entrega del pollo terminado tienen un efecto potencial sobre esta variable. A nivel de poblaciones, un bajo nivel de uniformidad, se correlaciona, por lo general, con pobres rendimientos productivos (Toudic, 2006). Si bien los factores que pueden conducir a una pobre uniformidad en un lote de pollos parrilleros son muy variados, algunos de ellos operan "desde fuera" del establecimiento (nivel de reproductores padres, manejo del huevo para incubar, los múltiples procesos que operan a nivel de planta de incubación, etc.), todo lo cual implica que el logro uniforme de un lote de pollos parrilleros, depende en buena medida de estos factores externos (Bramwell, 2003).

No obstante, no son menos importantes los aspectos que operan dentro del establecimiento, y que tienen que ver con la provisión de adecuadas condiciones del manejo de las aves, especialmente, las que se ofrecen durante las primeras semanas de vida; factores que eventualmente pueden causar una gran dispersión de pesos en el lote (Buxade Carbo, 1988). La falta de adecuadas condiciones de manejo del plantel a su ingreso al establecimiento es, usualmente, la primera causa de pobre uniformidad durante los primeros 10 días, ya que durante este periodo, los pollos incrementan su peso en un $20 \%$ diario, comparado con el $4 \%$ de incremento que tienen entre los 30 y 40 días. Además, los pollos destinan, proporcionalmente, una gran cantidad de su energía para mantener su homeostasis en la primera etapa de la vida (Penz, 1996).

Dentro de las condiciones ambientales como factores que inciden en la uniformidad, no puede descartarse los aspectos relacionados con la alimentación y nutrición de las aves, especialmente en pollos parrilleros de rápido crecimiento y alta demanda metabólica de principios nutritivos. En general, las deficiencias de lisina y otros aminoácidos inducen pobre uniformidad con un efecto no lineal, y una tendencia a la estabilización cuando los requerimientos de crecimiento son alcanzados (Toudic, 2006). Asimismo, las materias primas de baja digestibilidad conducen a un mayor deterioro en la uniformidad del lote (Penz, 1996).

La evaluación de la uniformidad en lotes de parrilleros puede transformarse en una información importante, después de un periodo de ensayo para ajustar el método, y puede ser usado como otro indicador técnico de la producción, en el mismo rango que la tasa de crecimiento, mortalidad e índice de conversión. Por tal motivo, el presente estudio describe la evolución del porcentaje de uniformidad de un lote de pollos parrilleros machos, donde el objetivo fue determinar el efecto de dietas balanceadas con distintas 
Cuadro 1. Materias primas $(\mathrm{kg})$ utilizadas en la elaboración de la ración de inicio y de terminación en pollos parrilleros

\begin{tabular}{lcccc}
\hline \multirow{2}{*}{ Insumos } & \multicolumn{2}{c}{ Ración de inicio } & \multicolumn{2}{c}{ Ración de acabado } \\
\cline { 2 - 5 } & $\begin{array}{c}\text { Alimento } \\
\text { forrajero }\end{array}$ & $\begin{array}{c}\text { Alimento } \\
\text { parrillero }\end{array}$ & $\begin{array}{c}\text { Alimento } \\
\text { forrajero }\end{array}$ & $\begin{array}{c}\text { Alimento } \\
\text { parrillero }\end{array}$ \\
\hline Maíz & 147.74 & 133.8 & 153.7 & 140.99 \\
Sal & 0.75 & 0.75 & 0.75 & 0.75 \\
Conchilla & 1.20 & 0.96 & 1.22 & 1.21 \\
Lisina & 0.37 & 0.00 & & \\
Metionina & 0.50 & 0.35 & 0.38 & 0.33 \\
Expeller de soja & 60.26 & 63.03 & 30.97 & 32.14 \\
Ceniza de hueso & 5.61 & 1.17 & 6.95 & 6.84 \\
Secuestrante de toxinas & 0.63 & 0.63 & 0.63 & 0.63 \\
Anticoccidiales & 0.13 & 0.13 & 0.13 & 0.13 \\
Núcleo vitamínico mineral & 0.63 & 0.63 & 0.63 & 0.63 \\
Poroto de soja desactivado & 29.45 & 36.08 & 54.53 & 66.26 \\
Pigmentante & - & - & 0.10 & 0.10 \\
Harina de carne & 2.74 & 12.50 & - & - \\
\hline Total (kg) & 250 & 250 & 250 & 250 \\
\hline
\end{tabular}

densidades nutricionales, sobre las relaciones de energía/proteína.

\section{MATERIALES Y MéTOdos}

Los ensayos se llevaron a cabo en un galpón cerrado con techo de zinc, paredes de mampostería, ventanas laterales, cielo raso de material aislante y piso de cemento alisado. El ciclo de producción tuvo una duración de 49 días, y fue dividido en dos fases: inicio (0 a 21 días) y acabado (21 a 49 días).

En cada ensayo se empleó 196 pollos parrilleros machos de una línea genética comercial, sexados por el método de las plumas primarias del ala (gen de emplume lento). Las aves se dividieron al azar en dos grupos experimentales, donde cada grupo fue alojado en siete corrales de $2 \mathrm{~m}^{2}$ cada uno.
El corral constituyó la unidad experimental del ensayo y se ubicaron 14 pollos en cada uno (densidad $=7$ aves por $\mathrm{m}^{2}$ ). Se ejecutaron las distintas etapas del ciclo de producción considerando como tratamiento variaciones cualitativas de la dieta: se evaluó una dieta tipo forrajera y otra de mayor nivel proteico, dieta parrillera. La composición de estas raciones se muestran en el Cuadro 1 y los resultados de los análisis químicos se presentan en los cuadros 2 y 3 . Tanto la dieta de inicio como la de acabado fueron, para cada tratamiento, isocalóricas, pero con diferencias en el aporte proteico, en términos de proteína bruta. Estas raciones fueron suministradas ad libitum durante todo el ciclo.

El agua se suministró en bebederos de plato con recipiente invertido con capacidad de 4 litros (60 $\mathrm{cm}$ de perímetro) a razón de uno por compartimiento ( $5 \mathrm{~cm}$ por ave). Se utilizó un comedero tolva $(125 \mathrm{~cm}$ de períme- 
Cuadro 2. Composición química y análisis de la ración de iniciador

\begin{tabular}{lccccc}
\hline & Alimento & $\begin{array}{c}\text { Base } \\
\text { seca }\end{array}$ & $\begin{array}{c}\text { Alimento } \\
\text { parrillero }\end{array}$ & $\begin{array}{c}\text { Base } \\
\text { seca }\end{array}$ \\
\hline Energía Met. & $\mathrm{Kcal} / \mathrm{kg}$ & 3000 & 3656 & 3000 & 3656 \\
Calcio & $\%$ & 0.95 & 1.69 & 0.95 & 1.66 \\
Fósforo disp. & $\%$ & 0.48 & 0.81 & 0.48 & 0.95 \\
Proteína & $\%$ & 20.0 & 20.73 & 22.7 & 22.23 \\
Grasa & $\%$ & 4.77 & 7.65 & 5.43 & 8.62 \\
Fibra & $\%$ & 3.40 & 3.45 & 3.66 & 3.82 \\
Ac. linoleico & $\%$ & 2.28 & & 2.43 & \\
Lisina & $\%$ & 1.17 & & 1.22 & \\
Metionina & $\%$ & 0.52 & & 0.49 & \\
Met + Cistina & $\%$ & 0.84 & & 0.85 & \\
Triptofano & $\%$ & 0.26 & & 0.26 & \\
Arginina & $\%$ & 1.33 & & 1.54 & \\
Isoleucina & $\%$ & 1.03 & & 1.13 & \\
Treonina & $\%$ & 0.79 & & 0.89 & \\
Xantofila & $\mathrm{mg} / \mathrm{kg}$ & 19.00 & & 17.00 & \\
Colina & $\mathrm{mg} / \mathrm{kg}$ & 1212.6 & & 1349 & \\
\hline Relación E:P & Ener:Prot & 150 & 176.36 & 132.15 & 164.46 \\
\hline
\end{tabular}

Cuadro 3. Composición química y análisis de la ración de acabado

\begin{tabular}{lccccc}
\hline & & $\begin{array}{c}\text { Alimento } \\
\text { forrajero }\end{array}$ & Base seca & $\begin{array}{c}\text { Alimento } \\
\text { parrillero }\end{array}$ & Base seca \\
\hline Energía Met. & Kcal/kg & 3150 & 3752 & 3150 & 3807 \\
Calcio & $\%$ & 0.95 & 1.52 & 0.95 & 1.33 \\
Fósforo disp. & $\%$ & 0.47 & 0.79 & 0.47 & 0.75 \\
Proteína & $\%$ & 18.5 & 18.29 & 20.0 & 19.52 \\
Grasa & $\%$ & 6.44 & 10.36 & 7.0 & 10.34 \\
Fibra & $\%$ & 3.1 & 4.03 & 3.3 & 4.15 \\
Ac. linoleico & $\%$ & 3.18 & & 3.5 & \\
Lisina & $\%$ & 0.98 & & 1.1 & \\
Metionina & $\%$ & 0.45 & & 0.45 & \\
Met + Cistina & $\%$ & 0.76 & & 0.78 & \\
Triptofano & $\%$ & 0.25 & & 0.27 & \\
Arginina & $\%$ & 1.23 & & 1.35 & \\
Isoleucina & $\%$ & 0.93 & & 1.00 & \\
Treonina & $\%$ & 0.75 & & 0.80 & \\
Xantofila & $\mathrm{mg} / \mathrm{kg}$ & 25 & & 24.16 & \\
Colina & $\mathrm{mg} / \mathrm{kg}$ & 1128 & & 1219 & \\
\hline Relación & & 170.2 & \multirow{2}{*}{205.14} & 150 & \multirow{2}{*}{195.03} \\
energía/proteína & & &
\end{tabular}


tro) de $6 \mathrm{~kg}$ de capacidad por cada corral (10 $\mathrm{cm}$ por ave). El piso fue cubierto con cama de cáscara de arroz de $5 \mathrm{~cm}$ de espesor, que se repuso parcialmente, según la necesidad, a lo largo del ciclo. En los primeros 20 días de vida, como fuente de calor, se emplearon estufas eléctricas con termostato, verificando la temperatura y humedad del ambiente mediante un higrotermómetro digital (higrotermómetro-Máximo / Mínimo digital Hygrotherm ${ }^{\circledR}$, TFA, Alemania). Durante la cría se trabajó con un fotoperiodo natural, manteniendo por la noche una luz piloto de baja intensidad localizada fuera del área de crianza.

Se utilizó un modelo experimental completamente aleatorizado, en el cual cada corral constituyó una unidad experimental y, a su vez, una repetición simple de cada tratamiento. De esta manera, se trabajó con siete réplicas por tratamiento. El número de repeticiones fue estimado en base al grado de precisión deseado y al desvío estándar estimado para cada variable (Poole, 1974) en función del comportamiento de las mismas en ensayos previos llevados a cabo por Sandoval et al. (1999) y Terraes et al. (2001).

Los valores de las variables se ingresaron en forma categórica en planillas y archivos informáticos para el análisis estadístico. Se presenta el promedio y la desviación estándar para la variable uniformidad al final del periodo de estudio (día 49). En el análisis de las diferencias entre tratamientos se aplicó un diseño de medidas repetidas en el tiempo para los valores obtenidos sobre cada unidad experimental, considerando límite un nivel de significancia del 5\%. En cada unidad experimental se registró semanalmente el porcentaje de uniformidad.

\section{Resultados y Discusión}

Al primer día de edad se observó un promedio de uniformidad para ambos tratamientos de $90 \%$, produciéndose en ambos un marcado descenso a los 7 días (55\% de uni- formidad). Al final de la campaña, los porcentajes de uniformidad fueron, para el tratamiento forrajero y parrillero, de $68 \pm 13 \%$ y $72 \pm 12 \%$, respectivamente, sin haber diferencias estadísticas (Fig. 1). Asimismo, en la Fig. 2, se observa que el porcentaje de uniformidad, en ambos tratamientos, tuvo una evolución similar durante el estudio, sin registrarse diferencias estadísticas entre ellos.

La mayor parte de autores señala que el porcentaje de uniformidad presente en un lote a su llegada correlaciona con factores que han actuado previamente (reproductores padres, proceso de incubación y nacimiento, traslado, etc.) (Buxade Carbo, 1988; Toudic, 2006), lo que indicaría que las aves recibidas provinieron de lotes de padres con adecuadas normas de manejo y con un buen proceso de incubación-nacimiento. Sin embargo, la bibliografía menciona que los procesos previos a la llegada de las aves al establecimiento pueden, eventualmente, manifestarse durante el ciclo de engorde (Donkoh, 1989; Oviedo-Rondon et al., 2009). En efecto, recientes investigaciones han encontrado que embriones que se desarrollan en condiciones de incubación con temperaturas bajas en los primeros nueve días en máquinas de edades múltiples, utilizarán la yema, en una proporción mayor, para compensar esta falta de calor, lo que puede llevar a deshidratación durante la crianza. Asimismo, los pollos cuyos huevos fueron sobrecalentados en los últimos cinco días de incubación pueden deshidratarse en la nacedora y durante la cría, lo cual se manifestaría en una falta de uniformidad del lote en etapas avanzadas del ciclo de engorde, independientemente del control de los otros factores que inciden sobre esta variable (Toudic, 2006).

La evolución de la uniformidad observada en el presente ensayo ha sido descrita por otros autores, quienes destacan que aunque las aves de un día presenten altos niveles de uniformidad, en los primeros 7 a 10 días, se produce, por lo general, un descenso en función de factores tales como la composición físico-química del alimento, el grado de 


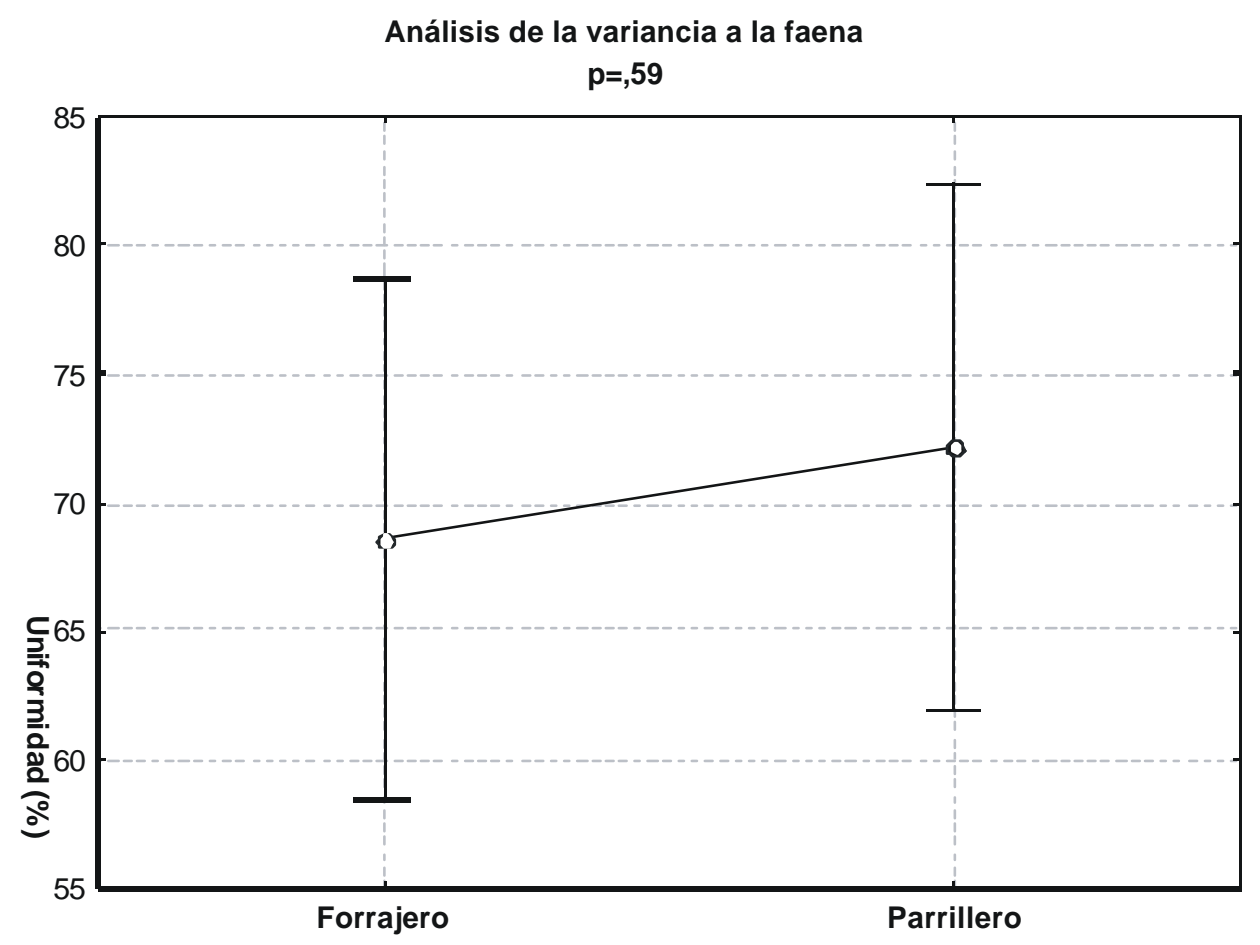

Figura 1. Análisis de la variancia para porcentaje de uniformidad según dietas a la edad de faena (49 días) en pollos parrilleros

reservas nutricionales disponibles al primer día de vida, y otros aspectos que coexisten en aves de igual peso corporal (North, 1978). Es común observar condiciones adecuadas de crianza en la primera etapa de la vida, a pesar de lo cual, los pollos con diferentes requerimientos nutricionales no puedan satisfacer todas sus necesidades en relación con el medio ambiente y, por lo tanto, disminuyen los porcentajes de uniformidad (Toudic, 2006).

La caída de los porcentajes de uniformidad a los 7 días de vida (Figs. 2 y 3 ) podría relacionarse con problemas de calidad del lote recibido en ambos grupos. Se ha estimado que más del $35 \%$ de la variabilidad en el peso corporal alcanzado al final del engorde depende, en líneas livianas, de la variación en el tamaño de los huevos incubables (North, 1978). Obviamente, la falta de adecuadas normas de manejo potenciarían los efectos de una pobre uniformidad inicial, proyectando la variabilidad del lote hasta la faena (Toudic, 2006), un hecho que no ha ocurrido en este estudio, donde la tendencia de la va- riable fue mejorando a lo largo del ciclo. En efecto, los porcentajes de uniformidad tendieron, en ambos tratamientos, a recuperarse paulatinamente a partir de la segunda semana de edad, aunque no se llegó a alcanzar los valores correspondientes al de un lote normal en términos de uniformidad (alrededor del $80 \%$ ). La falta de adecuadas normas de manejo general, no solo magnifica la variabilidad preexistente, sino que permite que no se logren adecuados porcentajes de uniformidad hacia el final del ciclo de engorde, comprometiendo la eficiencia del lote (North, 1993; Pontes Pontes y Castelló Llovet, 1995). En función de esto, es evidente que la recuperación de los porcentajes de uniformidad en los lotes en estudio no se hubiera logrado de no haber existido adecuadas normas de manejo general.

La evolución en el tiempo de la uniformidad, independientemente de los tratamientos, se observa en la Fig. 3, donde se presenta diferencia estadística en la variable analizada bajo este criterio. 


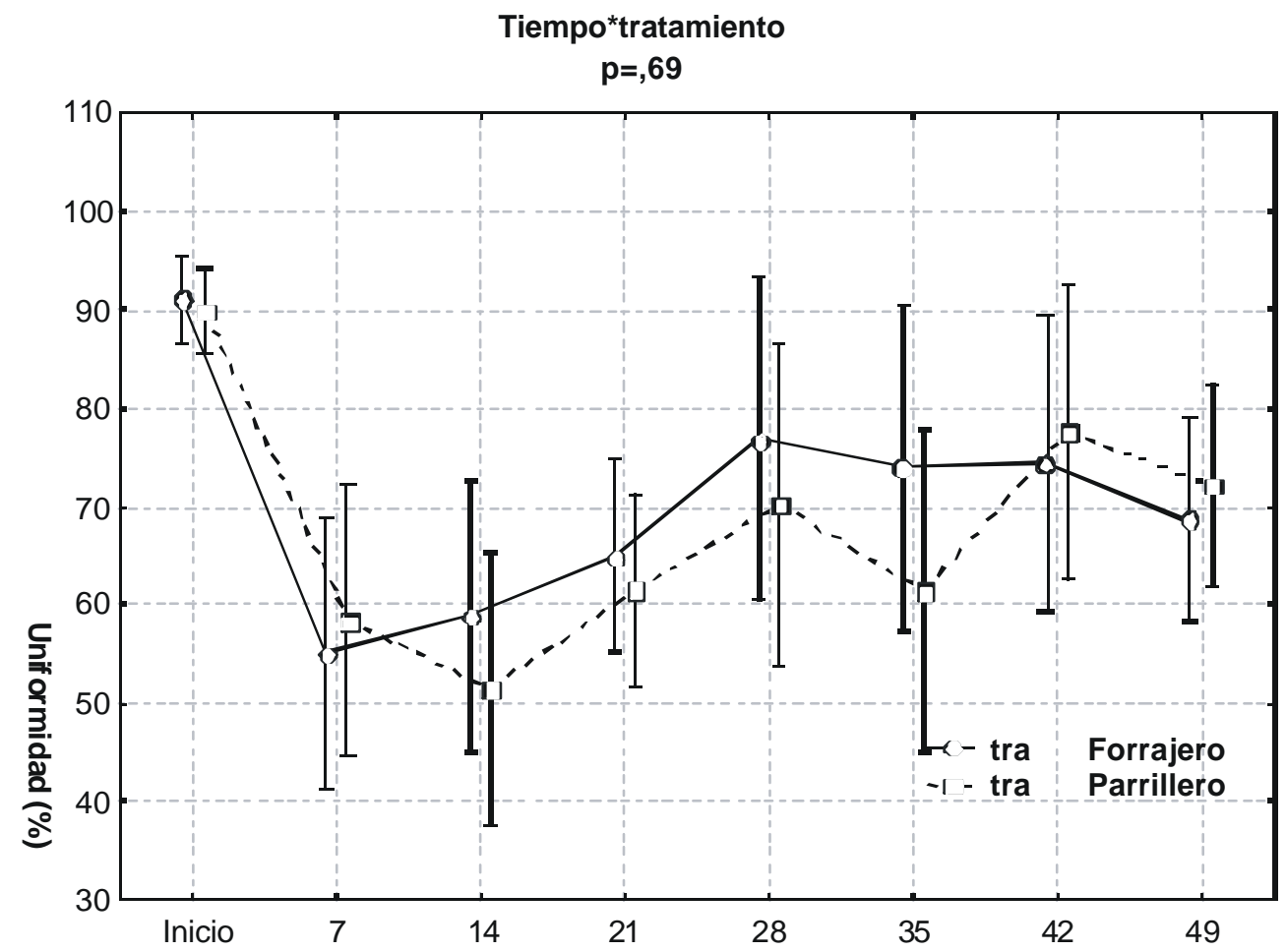

Figura 2. Asociación entre la edad y la dieta con el porcentaje de uniformidad en pollos parrilleros

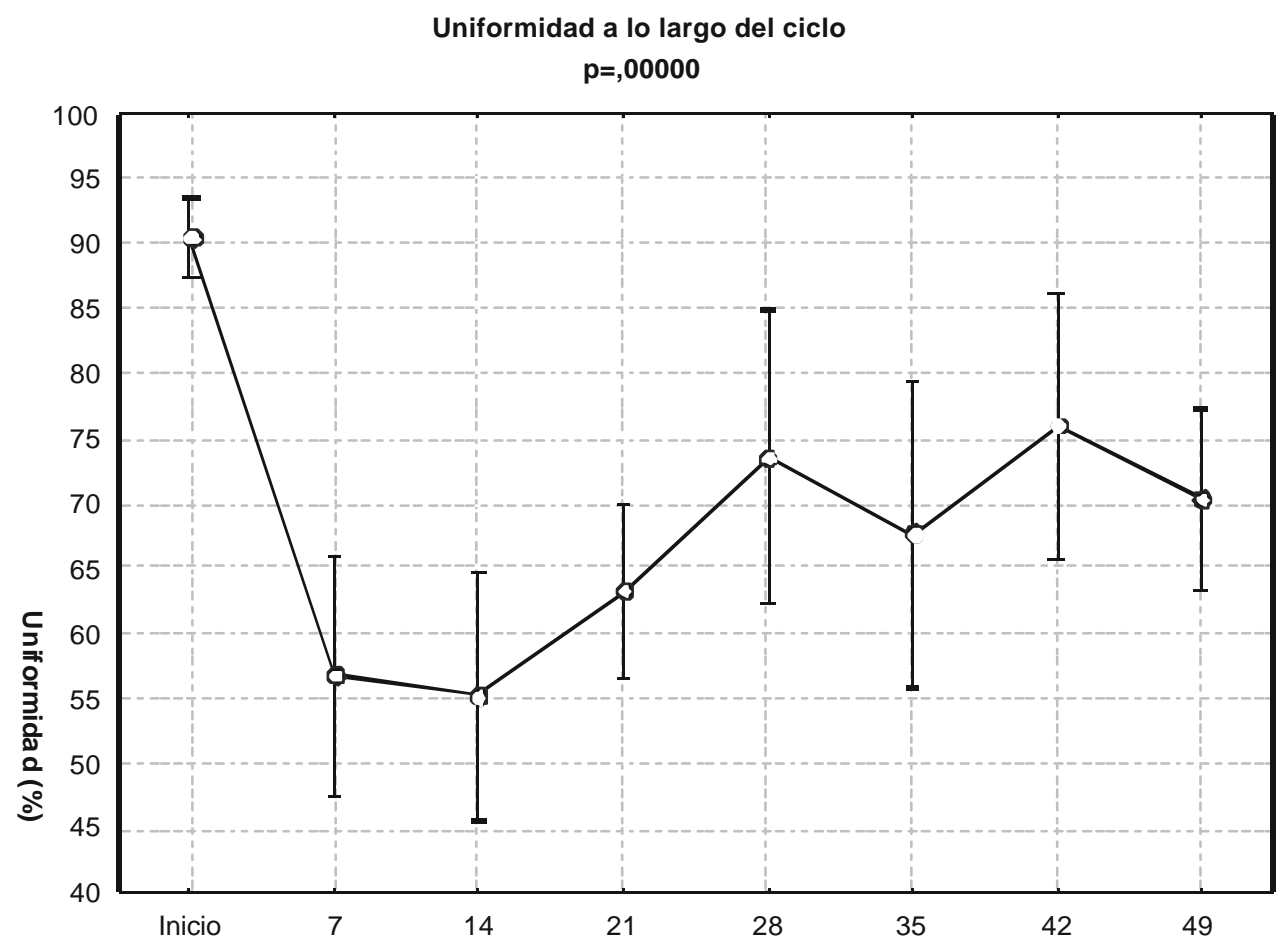

Figura 3. Porcentaje de uniformidad independientemente de los tratamientos (dietas) en pollos parrilleros 


\section{Conclusiones}

? Los resultados indican que pese a las diferencias en la composición química de las raciones evaluadas, se obtuvo una respuesta similar en la evolución de los porcentajes de uniformidad. Este resultado permite sugerir como dieta de elección la de mayor relación de energía/proteína; es decir, aquella con niveles proteicos más bajos.

? Es probable que en el comportamiento inicial del porcentaje de uniformidad hayan intervenido factores externos a los del ensayo, que explicarían la pérdida de uniformidad ocurrida durante la primera semana de vida, aunque no pueden descartarse la intervención de problemas a nivel del propio local de crianza. No obstante, las condiciones de manejo general demostraron ser eficaces para lograr la recuperación de las aves hasta valores que casi alcanzan aquellos de lotes uniformes.

\section{Limeratura Citada}

1. Bramwell K. 2003. Breeder flock uniformity can make a difference. [Internet]. Disponible en: http:// poultryandeggnews.com/poultrytimes/ focus/july2003/608568.html

2. Buxade Carbo C. 1988. El pollo de carne. $2^{\circ}$ ed. Madrid: Ed. Mundiprensa. 365 p.

3. Donkoh A. 1989. Ambient temperature: a factor affecting performance and physiological response of broiler chickens. Int J Biometeorol 33: 259-265.

4. North MO. 1978. Why look-alike pullets don't produce alike. Poultry Dig 37: 606612.

5. North MO. 1993. Manual de producción avícola. $3^{\circ}$ ed. México DF: El Manual Moderno. $829 \mathrm{p}$.

6. Oviedo-Rondon EO, Wineland MJ, Small S. 2009. Effect of incubation temperatures and chick transportation conditions on bone development and leg health. J Poultry Sci 18: 671-678.

7. Penz MA. 1996. Programas de alimentación para pollos. Industria Avícola 43(10): 18-20.

8. Pontes Pontes M, Castelló Llovet JA. 1995. Alimentación de las aves. Barcelona: Ed. Real Escuela de Avicultura. 540 p.

9. Sandoval GL, Terraes JC, Fernández RJ, Revidatti FA, Campos Vaca MV, Quevedo HD. 1999. Perfil bioquímico sérico y peso corporal en pollos con estrés físico inducido y hepatoprotección continua. En: XVI Congreso Latinoamericano de Avicultura. Lima, Perú.

10. Terraes JC, Sandoval GL, Fernández R.J, Revidatti FA. 2001. Respuesta a una maniobra inductora de estrés y al tratamiento con un producto hepatoprotector en pollos de engorde. Vet Méx 32: 195-200.

11. Toudic C. 2006. Evaluating uniformity in broiles - Factors affecting variation. Hubbard Technical Bulletin. [Internet]. Disponible en: http://www.hubbardbreeders.com/bulletins/index.php?id=28 